\title{
Teachers' intended classroom management strategies for students with ADHD: a cross-cultural study between South Korea and Germany
}

\author{
Yumi Lee $e^{A, B, C, D, E, F, G}$, Evelin Witruk W,C,D,E,F,G $^{A}$ \\ Institute of Psychology, Educational and Rehabilitation Psychology, University of Leipzig, Germany
}

\section{BACKGROUND}

The purpose of this study was to investigate Korean and German teachers' intentions of using classroom management strategies (CMS) for students with attention-deficit/ hyperactivity disorder (ADHD) based on the theory of reasoned action (TRA) and the theory of planned behavior (TPB).

PARTICIPANTS AND PROCEDURE

Participants were 639 Korean and 317 German teachers. Disproportional stratified sampling was used. As a result, 264 Korean and 264 German matched teachers were obtained. Kos's questionnaire was slightly modified. The survey instrument was distributed from September 2012 to December 2013. SPSS 22.0 was used to analyze the data.

\section{RESULTS}

Korean teachers were more influenced by norms of colleagues and parents than German teachers were. Teachers in both countries have more favorable attitudes towards positive-oriented CMS compared to negative-oriented CMS, and perceived themselves as being able to control all CMS in the classroom. The TRA proved to better predict both Korean and German teachers' intentions of using CMS compared to the TPB.

\section{CONCLUSIONS}

This study is an important step towards understanding teachers' CMS in the cultural context of Korea and Germany. The findings of this study will be an essential resource to develop an ADHD management manual based on theoretical and cultural perspectives, so that teachers in both countries are prepared for students with ADHD in their classroom, rather than give up on them.

KEY WORDS

hyperkinetic disorder; culture; Confucianism; TRA; TPB

CORRESPONDing AUthor - Yumi Lee, Ph.D., Institute of Psychology, Educational and Rehabilitation Psychology, University of Leipzig, Neumarkt 9-19, 04109 Leipzig, Germany, e-mail: yumi.lee@uni-leipzig.de authors' Contribution - A: Study design - B: Data collection - C: Statistical analysis - D: Data interpretation . E: Manuscript preparation · F: Literature search · G: Funds collection

TO CITE THIS ARTICLE - Lee, Y., \& Witruk, E. (2016). Teachers' intended classroom management strategies for students with ADHD: a cross-cultural study between South Korea and Germany. Current Issues in Personality Psychology, 4(2), 106-117.

RECEIVED 24.12.2015 - REVIEWED 30.04.2016 · ACCEPTED 13.05.2016 · PUBLISHED 20.06.2016 


\section{BACKGROUND}

Not to give up on students with ADHD, but rather to be prepared for them

The classroom is an important context for all students, and teachers have to manage students with diverse needs in their classroom (Bekle, 2004; Kos, 2004; Shin \& Koh, 2007). Effective implementation of classroom management strategies (CMS) is essential for the academic progress of all students as well as emotional well-being (DuPaul \& Power, 2008; Jung \& Choi, 2010), and of course students with attention-deficit/hyperactivity disorder (ADHD) are no exception (Lee \& Witruk, 2013). The success of students with ADHD in the classroom is mainly based on how teachers handle their problematic behaviors (Greene, Beszterczey, Katzenstein, Park, \& Goring, 2002; Hedin, Mason, \& Gaffney, 2011). Therefore, it is very important for teachers to be able to manage each student's personal, emotional, and social needs (Arcia, Frank, Sanchez-LaCay, \& Fernáindez, 2000 ), which in turn results in positive consequences as well as future success for students with ADHD (DuPaul \& Power, 2008; Montague \& Warger, 1997; Ohan, Cormier, Hepp, Visser, \& Strain, 2008).

Numerous studies have shown that teachers believed that managing students with ADHD requires more time and energy (Blume-D'Ausilio, 2005; Guyer, 2000). Teachers find that they have to modify their teaching strategies when they have students with ADHD in the classroom (Abikoff et al., 2002; Kos, 2004). In addition, teachers are concerned about social difficulties, especially the problematic behavior of students with ADHD in the classroom (Barkley, 2007; Groth, 2007; Joo \& Jeong, 2007). Teachers generally felt that acting-out behavior (externalizing problems) such as hyperactivity and impulsivity are more problematic than withdrawn and inattentive behavior (internalizing problems) such as lack of attention, which is less disruptive in the classroom environment (Cordier, Bundy, Hocking, \& Einfeld, 2010; Lee \& Witruk, 2013; Norvilitis \& Fang, 2005; Shin $\&$ Koh, 2007).

\section{CLASSROOM MANAGEMENT STRATEGIES FOR STUDENTS WITH ADHD}

In 1999, South Australia's Department of Education, Training and Employment (DETE) investigated a working document for teachers to provide classroom management strategies (CMS) for students with ADHD-like difficulties, including corrective strategies (reinforcement, negative consequences, planned ignoring), and environmental adaptation and positive programming and teaching (i.e., organizing the classroom and curriculum; proactive strategies). In 2008, Kos adapted these two strategies, with one more strategy, namely that of emotional support. Specific definitions of corrective strategies from the DETE (1999; also adapted from Kos 2004) are as follows.

Corrective strategies are behavioral management strategies which are frequently used to increase appropriate behavior as well as to decrease inappropriate behavior (DuPaul \& Eckert, 1998). Reinforcements include praising and rewarding the student for being good and doing the right thing. The aim of reinforcement is to increase the student's appropriate behavior. Negative consequences include reprimands, removal of privileges, the use of time out, and planned ignoring. The aim of negative consequences is to decrease the student's inappropriate behavior (Emmer, Evertson, \& Worsham, 2009; Shin \& Koh, 2007).

Positive reinforcement is the most frequently used and effective strategy for students with ADHD. Negative consequences and planned ignoring are also commonly used to effectively manage students with ADHD (Kos, 2008; Murray, 2009). For example, teachers can use planned ignoring as a strategy when students with ADHD are positively reinforced by teachers' attention. Punishment is not an effective strategy for students with ADHD when students are attention-seeking, because this strategy may serve to strengthen student's inappropriate behavior even if teachers were aiming to reduce it. Furthermore, teachers should use the above-mentioned strategies to achieve positive consequences for students' appropriate behavior (DuPaul \& Eckert, 1998; Emmer et al., 2009; Jung \& Choi, 2010).

Proactive strategies are commonly named proactive strategies or antecedent stimulus control, or organizing the classroom and curriculum. According to the DETE (1999), this environmental adaptation is divided into two categories as follows: (a) environmental adaptation is the strategy in which teachers establish an 'active' and a 'quiet' area within the room, so that distracters are identified in advance; (b) positive programming allows students with ADHD extra time for tasks, breaking tasks into smaller steps, and providing set choices during free time activities (Kos, 2004).

Kos (2004) and Murray (2009) found that organization of the classroom and curriculum are the most effective and beneficial strategies for Australian teachers, who show a very favorable attitude toward these strategies. These proactive strategies include measures that teachers can undertake before students with ADHD have a chance to misbehave, such as organizing seating arrangements, lowering the level of assignments, allowing short breaks between tasks, and working on a one-to-one basis with the student. Students with ADHD perform in the classroom better when the classroom is highly structured, has minimal sensory distractions, and if they 
sit in the middle-front of the classroom (Montague \& Warger, 1997) as well as when the curriculum is suited to their ability and they have permission to have a break during the lesson (DuPaul \& Power, 2008; Kos, 2004).

Emotional support includes counseling, adding activities to increase self-esteem, and showing the student care and attention, so that students are able to build upon their strengths (Kos, 2004). The DETE (1999) recommended that teachers should recognize and try to build upon the strengths of students with ADHD as well as to develop CMS in order to address potential problems which may occur at the students' home. Kos (2004) named this strategy emotional support (e.g., showing the student care and attention) in her research. According to Kos (2004) and Murray (2009), teachers believe that emotional support is effective and beneficial. In addition, they have a favorable attitude towards this strategy.

\section{THEORIES OF REASONED ACTION AND PLANNED BEHAVIOR}

Ajzen and Fishbein (1967) developed the theory of reasoned action (TRA) (adapted from Ajzen \& Fishbein, 2005). Later, in 1991, Ajzen developed the theory of planned behavior (TPB) by adding perceived behavior control (PBC) (Ajzen, 1991) (see Figure 1).

Both TRA and TPB aim to explain the relationship between attitude and behavior, and have shown significant results in the prediction of behavioral intention and specific behavior of interest (Ajzen, 1991; Fishbein \& Ajzen, 1975) within school settings for teaching children with disabilities (Theodorakis, Bagiatis, \& Goudas, 1995). With regard to comparing the two theories, contradictory results were found. Some studies found that TRA is better (e.g., Webb \& Sheeran, 2006), whereas other studies reported that TPB is a better theory to predict individuals behavior (e.g., Armitage \& Conner, 2001).

The theory of reasoned action (TRA). The TRA has often been studied as a theoretical framework to investigate the relationship between attitudes and behavior, as well as to predict and understand individuals' behavior in specific contexts, involving three major constructs (i.e., TRA predictors) a) attitude toward behavior, b) subjective norms, and c) intention (Fishbein \& Ajzen, 1975), which assess individuals' behavior through intentions (Ajzen \& Fishbein, 1980) (see Figure 1). Hence, the TRA assumes that people are engaged in a particular behavior (whether they intend to perform it or not) after making their decision, and this procedure includes the following three steps: The first step is to understand an individual's behavior to clearly define the particular behavior. The TRA is an effective model to predict individuals' behavior, which they have chosen to perform voluntarily. The second step is an intention which should be understood as an indicator of how individuals are willing to try to perform a particular behavior. An individual's intention to perform a specific behavior is explained as the immediate determinant factor of an individual's actual behavior, which means that a person behaves according to their intentions, and the stronger the intention they have, the more they will engage in an actual behavior. The third step is an individual's attitude towards the behavior and its subjective norms. These two constructs are directly determined by a person's intention to engage in a given particular behavior. For example, attitude towards the behavior refers to an individual's evaluation of performing that particular behavior and subjective norm factors refer to the perception of an individual about how social pressure affects whether they perform a particular behavior or not.

The theory of planned behavior (TPB). Ajzen (1991) addressed the fact that individuals' behavior

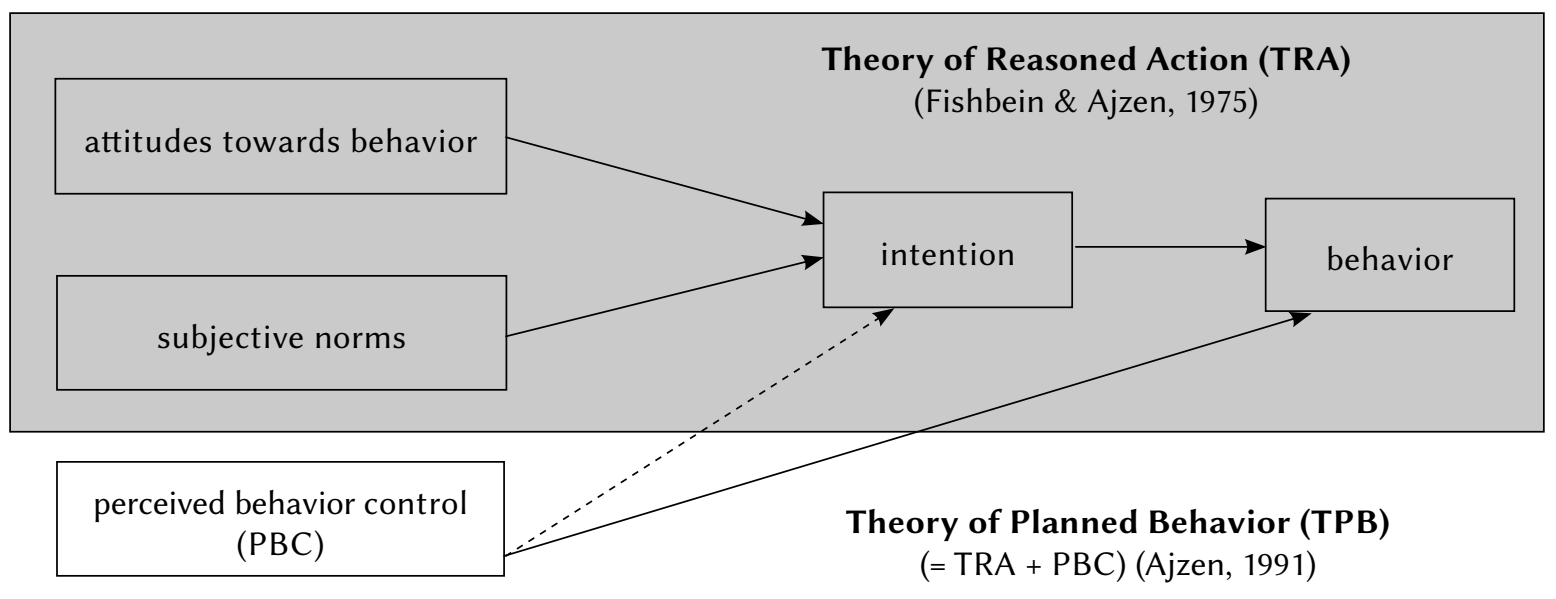

Figure 1. Theory of Reasoned Action (TRA) and Theory of Planned Behavior (TPB). 
differs according to their perceived behavior control (PBC), which influences peoples' behavior change (see Figure 1). Because of the PBC, more complex behaviors (e.g., managing students' problematic behavior) can accurately be assessed, which was poorly predicted in the TRA (Armitage \& Conner, 2001). The $\mathrm{PBC}$ refers to a subjective individual's assessment on how easy or difficult it is to carry out a particular behavior. In TPB, the individuals' subjective beliefs are assessed by measuring the level of perceived control over performing a particular behavior (Ajzen, 1991), for example, when teachers intend to use emotional support to manage the problematic behavior of students with ADHD and think they are able to control it, whether by using emotional support or not as a CMS (Kos, 2008). As shown in Figure 1, PBC has a direct influence on intention, over the attitudes towards behavior and subjective norms. Theoretically, if individuals lack PBC, and yet have favorable attitudes and subjective norms towards behavior, they may not have a strong intention to perform a specific behavior (Ajzen, 1991). Perceived behavior control is also indirectly linked to behavior, when $\mathrm{PBC}$ and actual behavior control are not remarkably different. However, when there are remarkable gaps between two perceived and actual behavioral controls, only indirect relationships will be shown.

TRA and TPB in educational settings. According to the TRA, the behavior of interest could be the teachers' use of reinforcement on students with ADHD. For example, teachers may decide to use reinforcement to manage students with ADHD. Then teachers' attitudes towards these strategies will be changed whether or not teachers think that strategy is effective and beneficial to manage students with ADHD. In addition, subjective norms may be assessed as to how teachers consider other peoples' perceptions to manage students with ADHD (Webb \& Sheeran, 2006). In addition, the TPB is also used to explain teachers' CMS regarding students with ADHD. For example, the TPB can be used to investigate teachers' use of proactive strategies to manage students with ADHD. In this instance, teachers' intentions will be measured as to whether teachers are willing to try this strategy to manage students with ADHD (Armitage \& Conner, 2001; Kos, 2008).

In 2008, Kos assessed the TRA and the TPB to identify primary school teachers' behavioral intentions of using CMS. She found that TRA predictors (e.g., attitudes toward CMS, colleagues and parental norms) were able to explain teachers' intentions of using negative-oriented strategies. However, colleagues' and parental subjective norms did not provide a significant impact on their intentions of using all strategies, which was also found by Armitage and Conner (2001). In Kos's study, however, the TPB showed a partial improvement (over the TRA), and neither colleagues' nor parental subjective norms provided a significant impact on the teachers' intention to use all strategies.

\section{CULTURE: SOUTH KOREA AND GERMANY}

Hofstede (2001) emphasized that culture is frequently observed at the national level when it is compared to the international environment. Thus, it is necessary to share the specific national culture and values which may represent individuals' own country in order to understand their perceptions and behavior within a culture as well as across cultures (Singh, 2008).

Individualism versus collectivism. With regard to the theoretical and empirical cultural context, the dimension of "individualism" versus "collectivism" is the most widespread influence among cross-cultural research (Hofstede, 2001; Triandis, 2001) as it differentiates between two major value systems in various cultures, which makes it possible to predict differences in behavior based on traditional beliefs within each culture as well as between cultures (Moon, 2011; Singh, 2008).

People in more individualistic cultures (e.g., Western Europe, North America) perceive themselves as being "independent" with their own needs, which is related to independence, autonomy in choice and action, equality, uniqueness, achievement orientation, and competition group (Hofstede, 2001; Triandis, 2001). According to Hofstede (2001), Germany is classified under individualism (individualism score: 67 ), where it is typical to think in the " $P$ " form, which is based on each person. Individualism in Germany emerged in the 1970s (as cited by Hoppe-Graff \& Kim, 2005, p. 8), when identification with social groups became less important. Therefore, Germany placed greater priority on personal goals, and primarily looking after one's own interests.

People in more collectivistic cultures (e.g., Asia, South America, and Africa) see themselves as being "interdependent", belonging to a group (Hofstede, 2001; Triandis, 2001), which is related to the connection with others, conformity with group norms, and obedience of authority. According to Hofstede (2001), Korea $^{1}$ defines itself under collectivism (individualism score: 18), where it is typical to think in the "we" form with values based on society. Collectivism in Korea emerged in the 1970s (as cited by Hoppe-Graff \& Kim, 2005, p. 10), when identification with social groups became more important. Therefore, Koreans make an attempt to maintain harmony with others and define themselves in the context of their society and relationship to their group.

Individualism and collectivism with vertical and horizontal relationships. Previous studies discussed that the dimension of "individualism versus col- 


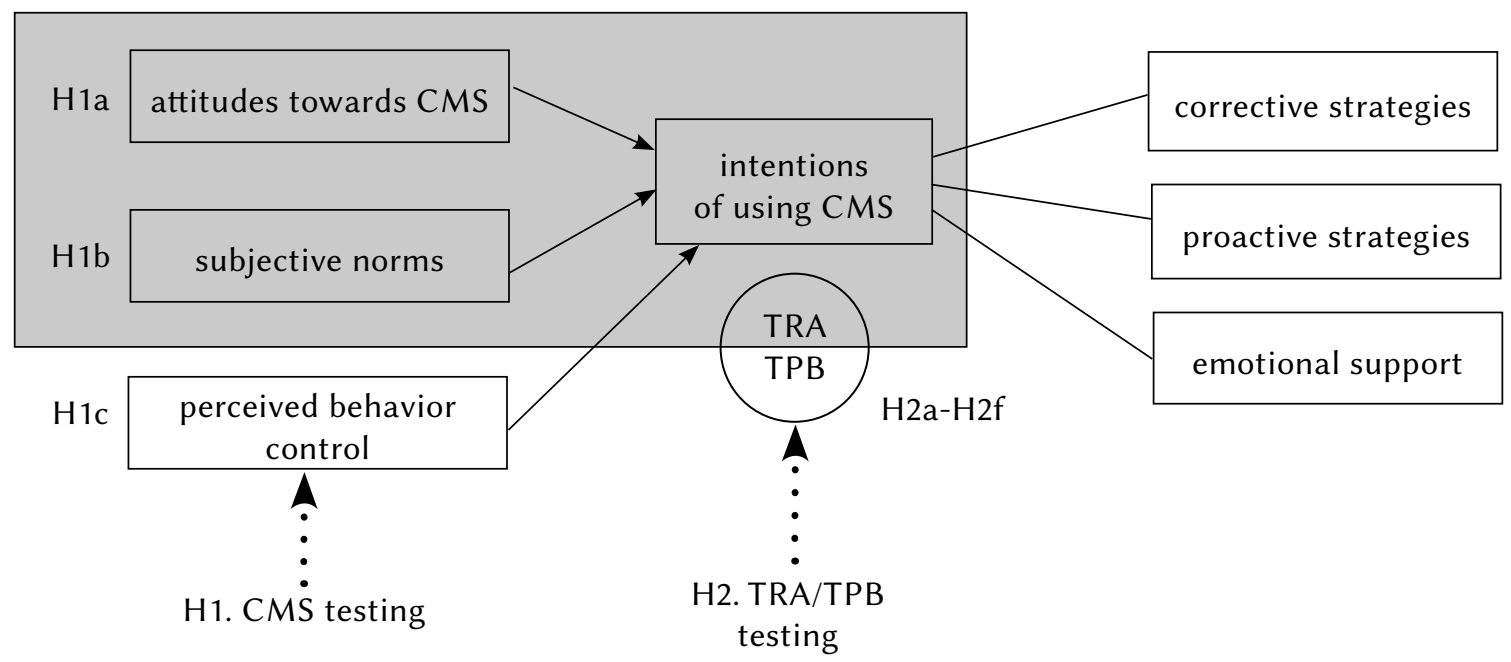

Note. $\mathrm{H}$ - hypothesis; CMS - classroom managements strategies; subjective norms - colleagues' and parents' norms; PBC - perceived behavior control over the CMS; TRA - theory of reasoned action; TPB - theory of planned behavior

Figure 2. Conceptual Research Model.

lectivism" is not enough to specifically understand culture. The alternative views of "vertical or horizontal" relationships can explain unique culture better, which is related to personal value (Shavitt, Lalwani, Zhang, \& Torelli, 2006; Singelis, Triandis, Bhawuk, \& Gelfand, 1995). People in these vertical relationships consider themselves to be different from other people. On the other hand, horizontal relationship cultures stress all peoples' equality and develop a flat social hierarchy (Shavitt et al., 2006; Triandis \& Gelfand, 1998).

Both Korea and Germany belong to the group of "vertical" relationships (Hoppe-Graff \& Kim, 2005). Thus, they stress the "hierarchy" of persons from one another according to their (social) rank and construct a strict social hierarchy. Collectivism in Korea is vertical, with a great emphasis on the "hierarchy" (in the form of a vertical relationship) and "integrity of the in-group" (as a collectivistic culture) whereby they are willing to sacrifice their personal goals for in-group goals and support "competition" of their ingroups with out-groups. Individualism in Germany is also vertical, with great emphasis on the "hierarchy" (as a vertical relationship) and "freedom" (as an individualistic culture) and less value placed on equality (Singelis et al., 1995; Triandis \& Gelfand, 1998).

Confucianism. Confucianism is a philosophical and ethical doctrine which stressed human morality and right action (Hoppe-Graff \& Kim, 2005). According to Confucian doctrine, Korean cultural values are in "harmony by morality". In order to maintain harmony within the group, individuals need to know the social order based on hierarchies of age, social status, and family. For example, lower hierarchs (e.g., students) are expected to respect by obeying higher hierarchs (e.g., teachers), and higher hierarchs are expected to have authority in order to care for lower hierarchs. Therefore, any disruptive behavior which disrupts the harmony is perceived as "abnormal" based on Confucian culture (Moon, 2011).

\section{THE CURRENT STUDY}

The purpose of this study was to investigate teachers' intentions of using classroom management strategies (CMS) based on the theory of reasoned action (TRA: Fishbein \& Ajzen, 1975) and the theory of planned behavior (TPB: Ajzen, 1991) (see Figure 2).

\section{RESEARCH QUESTIONS (RQ)}

1. Are there significant differences between Korea and Germany in terms of teachers' attitudes towards CMS (positive and negative-oriented CMS) (RQ 1a), subjective norms (colleagues and parents norms) (RQ 1b), and perceived behavior control over CMS (RQ 1c)? [CMS testing]

2. How do the TRA and the TPB offer a significant contribution to predict Korean and German teachers' intentions to use CMS (corrective strategy, proactive strategy, and emotional support) (RQ2aRQ2f)? [TRA/TPB testing]

\section{HYPOTHESES}

Both Korean and German teachers will have favorable attitudes towards positive-oriented CMS rather than negative-oriented CMS (H1a); Korean teachers 
Table 1

Grouped frequency of responses for teachers' personal details

\begin{tabular}{|c|c|c|c|c|c|}
\hline \multirow{2}{*}{\multicolumn{2}{|c|}{ Variables }} & \multicolumn{2}{|c|}{$\begin{array}{c}\text { Korea } \\
(n=264)\end{array}$} & \multicolumn{2}{|c|}{$\begin{array}{r}\text { Germany } \\
(n=264)\end{array}$} \\
\hline & & Frequency & Percent & Frequency & Percent \\
\hline \multicolumn{6}{|c|}{ Matched Variables } \\
\hline \multirow{2}{*}{ Gender } & Male & 51 & 19.30 & 51 & 19.30 \\
\hline & Female & 213 & 80.70 & 213 & 80.70 \\
\hline \multirow{4}{*}{ Age } & $<30$ years old & 81 & 30.70 & 81 & 30.70 \\
\hline & $30-39$ & 56 & 21.20 & 56 & 21.20 \\
\hline & $40-49$ & 68 & 25.80 & 68 & 25.80 \\
\hline & $50-59$ & 59 & 22.30 & 59 & 22.30 \\
\hline \multirow{2}{*}{$\begin{array}{l}\text { Number of } \\
\text { teaching years }\end{array}$} & Less than 10 & 132 & 50.00 & 132 & 50.00 \\
\hline & More than 10 & 132 & 50.00 & 132 & 50.00 \\
\hline \multirow{2}{*}{$\begin{array}{c}\text { Place where teachers } \\
\text { work }\end{array}$} & Primary & 132 & 50.00 & 132 & 50.00 \\
\hline & Secondary & 132 & 50.00 & 132 & 50.00 \\
\hline \multicolumn{6}{|c|}{ Unmatched variables } \\
\hline \multirow{5}{*}{$\begin{array}{l}\text { Class } \\
\text { size }\end{array}$} & Less than 10 & 16 & 6.10 & 2 & 0.80 \\
\hline & $10-20$ & 25 & 9.50 & 61 & 23.10 \\
\hline & $21-30$ & 101 & 38.30 & 201 & 76.20 \\
\hline & $31-40$ & 110 & 41.60 & 0 & 0 \\
\hline & More than 40 & 12 & 4.50 & 0 & 0 \\
\hline \multirow{2}{*}{$\begin{array}{l}\text { University } \\
\text { education }\end{array}$} & Yes & 75 & 28.40 & 62 & 23.50 \\
\hline & No & 189 & 71.60 & 202 & 76.50 \\
\hline
\end{tabular}

Note. University education = teachers' university education involved skill development to manage students with ADHD.

will be more influenced by both subjective norms compared to German teachers (H1b); German teachers perceive themselves as being able to control students with ADHD by using CMS compared to Korean teachers (H1c).

Both the TRA and TPB will offer a significant contribution to predict Korean and German teachers' intentions of using CMS: a) corrective strategies (Korea: H2a, Germany: H2b); b) proactive strategies (Korea: H2c, Germany: H2d); and c) emotional support (Korea: H2e, Germany: H2f).

\section{PARTICIPANTS AND PROCEDURE}

\section{PARTICIPANTS}

Participants were teachers from Korea and Germany. In total, 639 Korean teachers and 317 German teachers participated in this study. Disproportional stratified sampling was used for the purpose of equaling out two culturally different samples. Four criteria were adopted: a) teachers' gender, b) age, c) number of teaching years, d) the place where teachers work. As a result of the sampling procedure, 264 Korean teachers were matched to 264 German teachers, for the same number of cases (see Table 1).

\section{SURVEY INSTRUMENT}

Kos's (2004) questionnaire was adapted with permission. A cover letter describing this study was composed by the researcher with slight modifications for the two countries. Translation/back-translation and item review were conducted by professionals in order to confirm the equivalence of the survey instrument in the two different cultures. A pilot study was then undertaken in order to modify the survey instrument for the actual study.

In total, 37 items were measured to assess the TRA and the TPB, involving (a) attitudes towards CMS ("As a means of managing students with ADHD in the classroom, reinforcement is effective"; $\alpha=.75$ ), (b) perceived behavior control (PBC) ("I have a lot of control over whether I use reinforcement”; $\alpha=.77$ ), 
Table 2

Results of all CMS variables

\begin{tabular}{|c|c|c|c|c|c|c|c|}
\hline & & \multicolumn{2}{|c|}{ Korea } & \multicolumn{2}{|c|}{ Germany } & \multirow[t]{2}{*}{$t$} & \multirow[t]{2}{*}{$d$} \\
\hline & & $M$ & $S D$ & $M$ & $S D$ & & \\
\hline \multicolumn{8}{|c|}{ Teachers' Attitudes Towards CMS } \\
\hline \multirow{3}{*}{$\begin{array}{l}\text { Corrective } \\
\text { strategies }\end{array}$} & rein & 6.80 & 1.21 & 6.93 & 1.05 & -1.34 & .11 \\
\hline & nega & 4.85 & 1.62 & 5.85 & 16.88 & -0.96 & .08 \\
\hline & igno & 5.24 & 1.59 & 5.74 & 11.98 & -0.67 & .05 \\
\hline \multicolumn{2}{|c|}{ Proactive strategies } & 6.40 & 1.24 & 6.35 & 1.36 & 0.45 & .03 \\
\hline \multicolumn{2}{|c|}{ Emotional support } & 7.07 & 1.15 & 6.87 & 1.08 & $2.08^{*}$ & .18 \\
\hline \multicolumn{8}{|c|}{ Teachers' Subjective Norms } \\
\hline \multicolumn{2}{|c|}{ Colleagues' norms } & 18.57 & 2.81 & 17.11 & 2.85 & $5.92^{* * *}$ & .52 \\
\hline \multirow{2}{*}{\multicolumn{2}{|c|}{ Parents' norms }} & 18.06 & 2.65 & 17.27 & 2.78 & $3.31^{* *}$ & .18 \\
\hline & & \multicolumn{6}{|c|}{ Teachers' Perceived Behavior Control } \\
\hline \multicolumn{2}{|c|}{ PBC over CMS } & 44.08 & 5.11 & 43.64 & 5.41 & 0.97 & .08 \\
\hline
\end{tabular}

Note. rein - Reinforcement; nega - Negative consequences; igno - Planned ignoring; each CMS ( $\min =2$; max = 8); both subjective norms $(\min =6 ; \max =24) ; \mathrm{PBC}-$ perceived behavior control $(\min =15 ; \max =60)$; Cohen's effect size $(d)=$ small .2 , medium .5 , large $.8 ;{ }^{* *} p<.001,{ }^{* *} p<.01,{ }^{*} p<.05$.

(c) colleagues' norms ("It is important to me that other staff approve of the way I manage students with ADHD"; $\alpha=.68$ ), and (d) parents' norms ("I would use reinforcement to manage a student with $\mathrm{ADHD}$ if the parent(s) thought I should"; $\alpha=.73$ ). All items for CMS were to be checked based on a 4-point-Likert type scale ( 1 = strongly agree, 4 = strongly disagree). The higher scores represent stronger beliefs about different CMS for students with ADHD.

\section{DATA COLLECTION}

The data were collected in Korea from September to December in 2012 and in Germany from January to December in 2013. For the Korean data, the first author directly contacted one teacher in person who was in charge (of each school) and also visited the graduate school of the Korean National University of Education to meet graduate students of counseling psychology (whose professionals are teachers) to request participation. For the German data, the second author received permission from the Saxon Education Agency, and then each school was contacted for participation. In addition, one professor from the Department of Education (University of Leipzig) contacted the person who is in charge of trainee teachers to request cooperation.

\section{DATA ANALYSIS}

Mean analysis and hierarchical multiple regression analysis were conducted to assess the cross-cultural similarities and differences of the research variables, as well as to test the TRA and the TPB for confirming teachers' intentions of using CMS for the student with ADHD.

\section{RESULTS}

\section{HYPOTHESIS 1: CMS TESTING}

The results of hypothesis 1 (cross-cultural similarities and differences of all CMS variables) are shown in Table 2.

Hypothesis 1a: Teachers' attitudes towards CMS. Both Korean and German teachers have more favorable attitudes towards positive-oriented CMS (reinforcement, proactive strategies, and emotional support) compared to negative-oriented CMS (negative consequences and planned ignoring). Therefore, hypothesis 1a is accepted.

Hypothesis 1b: Subjective norms. Korean teachers were more influenced by others (both parents and colleagues) than German teachers: (a) colleague norms: Korea $(M=18.57, S D=2.81)$ and Germany $(M=17.11, S D=2.85), t(526)=5.92, p<.001$, $d=.52$; (b) parental norms: Korea $(M=18.06$, $S D=2.65)$ and Germany $(M=17.27, S D=2.78)$, $t(526)=3.31, p=.001, d=.18$. Thus, hypothesis $1 \mathrm{~b}$ was accepted.

Hypothesis 1c: PBC over CMS. No significant difference was found between Korean $(M=44.08$, $S D=5.11)$ and German teachers $(M=43.64, S D=5.41)$, $t(526)=.93, p=.331, d=.08$, which means that both 
Table 3

Results of teachers' intentions of using CMS: TRA and TPB testing

\begin{tabular}{|c|c|c|c|c|c|c|}
\hline & \multicolumn{3}{|c|}{ Korea } & \multicolumn{3}{|c|}{ Germany } \\
\hline & $\beta$ & $s r^{2}$ & $p$ & $\beta$ & $s r^{2}$ & $p$ \\
\hline \multicolumn{7}{|c|}{ Teachers' Intentions of Using Corrective Strategies } \\
\hline Step 1 & \multicolumn{3}{|c|}{$R^{2}=.059, \operatorname{Sig} F=.001$} & \multicolumn{3}{|c|}{$R^{2}=.177, \operatorname{Sig} F=.000$} \\
\hline Att: Corrective & .103 & .007 & .151 & .250 & .041 & .000 \\
\hline Colleagues' norm & .037 & .000 & .681 & .162 & .015 & .028 \\
\hline Parents' norm & .079 & .002 & .363 & .117 & .010 & .071 \\
\hline Step 2 & \multicolumn{3}{|c|}{$R^{2 \text { change }}=.005$, Sig $F^{\text {change }}=.237$} & \multicolumn{3}{|c|}{$R^{2 \text { change }}=.001$, Sig $F^{\text {change }}=.578$} \\
\hline PBC & .087 & .005 & .223 & -.001 & .000 & .986 \\
\hline \multicolumn{7}{|c|}{ Teachers' Intentions of Using Proactive Strategies } \\
\hline Step 1 & \multicolumn{3}{|c|}{$R^{2}=.094$, Sig $F=.000$} & \multicolumn{3}{|c|}{$R^{2}=.120$, Sig $F=.000$} \\
\hline Att: Proactive & .126 & .011 & .064 & .159 & .020 & .015 \\
\hline Colleagues' norm & .050 & .001 & .514 & .026 & .000 & .712 \\
\hline Parents' norm & .178 & .018 & .021 & .200 & .028 & .004 \\
\hline Step 2 & \multicolumn{3}{|c|}{$R^{2 \text { change }}=.001$, Sig $F^{\text {change }}=.522$} & \multicolumn{3}{|c|}{$R^{2 \text { change }}=.008$, Sig $F^{\text {change }}=.129$} \\
\hline PBC & .036 & .001 & .589 & .125 & .011 & .069 \\
\hline \multicolumn{7}{|c|}{ Teachers' Intentions of Using Emotional Support } \\
\hline Step 1 & \multicolumn{3}{|c|}{$R^{2}=.035$, Sig $F=.027$} & \multicolumn{3}{|c|}{$R^{2}=.025$, Sig $F=.089$} \\
\hline Att: Support & .095 & .006 & .179 & -.027 & .000 & .691 \\
\hline Colleagues' norm & .050 & .001 & .518 & -.066 & .003 & .357 \\
\hline Parents' norm & .050 & .001 & .538 & .154 & .132 & .031 \\
\hline Step 2 & \multicolumn{3}{|c|}{$R^{2 \text { change }}=.006$, Sig $F^{\text {change }}=.222$} & \multicolumn{3}{|c|}{$R^{2 \text { change }}=.018$, Sig $F^{\text {change }}=.027$} \\
\hline PBC & .056 & .002 & .429 & .148 & .123 & .046 \\
\hline
\end{tabular}

Note. Att: Corrective - attitudes toward corrective strategies; Att: Proactive - attitudes toward proactive strategies; Att: Support attitudes towards emotional support; PBC - perceived behavior control; standardized estimate - $\beta$; $R^{2}$ change - regression equation formed after each step; Sig $F^{\text {change }}$ - significance of the change in the regression equation formed after each step; $\mathrm{sr}^{2}$ and $p$ - individual predictors, the values for the variables in the final regression model; $\mathbf{s r}^{2}$ - squared semi-partial correlation.

Korean and German teachers perceived that they can control CMS. Therefore, hypothesis 1c was rejected.

\section{HYPOTHESIS 2: TRA/TPB TESTING}

The results of hypothesis 2 (teachers' intentions of using CMS: TRA and the TPB testing) are shown in Table 3.

Hypothesis 2a/2b: Corrective strategies. The TRA variables (a) attitude towards corrective strategies, (b) colleagues' norms, and (c) parents' norms (socalled TRA predictors) accounted for a significant proportion of the variance in teachers' intentions of using corrective strategies in Korea $\left(R^{2}=.06\right.$, $F(3,260)=5.46, p=.001)$ and in Germany $\left(R^{2}=.18\right.$, $F(3,260)=18.64, p<.001)$.

None of these three TRA-predictors alone had a significant effect on Korean teachers' intentions of using corrective strategies. For German teachers, on the other hand, two of the TRA predictors alone had a significant effect on German teachers' intentions of using corrective strategies, with $4.10 \%$ (for attitudes towards corrective strategies: $\beta=.25, p<.001$ ) and $1.50 \%$ (teacher norm: $\beta=.16, p=.028$ ) of the variance for these single predictors.

The PBC was then added to test the TPB. The model was not significantly improved in Korea $\left(R^{2 \text { change }}=\right.$ 
.01 , Sig $\left.F^{\text {change }}(4,259)=4.46, p=.237\right)$ or in Germany $\left(R^{2 \text { change }}=.001, \operatorname{Sig} F^{\text {change }}(4,259)=14.02, p=.578\right)$.

Hypothesis 2c/2d: Proactive strategies. The TRA showed a significant proportion of the variance for teachers' intentions of using proactive strategies in both countries: Korea $\left(R^{2}=.09, F(3,260)=9.02\right.$, $p<.001)$ and Germany $\left(R^{2}=.12, F(3,260)=11.77\right.$, $p<.001)$.

One of the TRA predictors (parents' norms) alone had a significant effect on Korean teachers' intentions of using proactive strategies $(\beta=.18, p=.021)$, with $1.80 \%$ of the variance for this single predictor. For German teachers, two of the TRA predictors (attitude towards proactive strategies and parents' norms) alone had a significant effect on their intentions of using proactive strategies, with $2.00 \%$ (for attitudes: $\beta=.16$, $p=.015$ ) and with $2.80 \%$ (parents norm: $\beta=.20, p=.004$ ) of the variance for this single predictor.

The TPB was not significantly improved in Korea $\left(R^{2}\right.$ change $\left.=.001, \operatorname{Sig} F^{\text {change }}(4,259)=6.85, p=.522\right)$ or in Germany $\left(R^{2 \text { change }}=.01\right.$, Sig $F^{\text {change }}(4,259)=9.45$, $p=.129)$.

Hypothesis 2e/2f: Emotional support. The TRA showed a significant proportion of the variance for Korean teachers' intentions of using emotional support $\left(R^{2}=.04, F(3,260)=3.11, p=.027\right)$, but not for German teachers $\left(R^{2}=.03, F(3,260)=2.19, p=.089\right)$.

None of these three TRA predictors alone had a significant effect on Korean teachers' intentions of using emotional support. However, one of the TRA predictors (parents' norms) alone had a significant effect on German teachers' intentions of using emotional support $(\beta=.15, p=.046)$, with $1.30 \%$ of the variance for this single predictor.

The PBC was entered to test the TPB, but the model was not significantly improved in Korea $\left(R^{2 \text { change }}=.01, \operatorname{Sig} F^{\text {change }}(4,259)=2.71, p=.222\right)$. On the other hand, the model was significantly improved in Germany $\left(R^{2}\right.$ change $=.02$, Sig $F^{\text {change }}(4,259)=2.26$, $p=.027)$. In addition, PBC alone had a significant effect on German teachers' intentions of using emotional support $(\beta=.15, p=.046)$, with $1.20 \%$ of the variance for this single predictor.

To sum up, the TRA proved to be a significant contribution to predicting both Korean and German teachers' intentions of using CMS (excluding German teachers' intentions of using emotional support). However, the TPB only proved to significantly contribute to predicting German teachers' intentions of using emotional support. Thus hypothesis 3 was partly accepted (the TRA was accepted and the TPB was rejected).

\section{DISCUSSION}

The purpose of this study was to investigate Korean and German teachers' intentions of using classroom management strategies (CMS) for students with ADHD based on the theory of reasoned action (TRA) and the theory of planned behavior (TPB).

A brief summary of results of testing each hypothesis is as follows:

Both Korean and German teachers have more favorable attitudes towards positive-oriented CMS (e.g., proactive strategies) compared to negative-oriented CMS (e.g., planned ignoring). Korean teachers were more influenced by colleagues' and parents' norms than German teachers were. Also, both Korean and German teachers perceived themselves as being able to control all CMS in the classroom.

The TRA proved to significantly contribute to predicting both Korean and German teachers' intentions of using CMS (excluding German teachers' intentions of using emotional support). On the other hand, the TPB proved to significantly contribute to predicting only German teachers' intentions of using emotional support.

\section{INTERPRETATION OF THE RESULTS}

Hypothesis 1a (attitudes towards CMS). Teachers in both countries had favorable attitudes towards positive-oriented CMS compared to negative-oriented CMS, which confirmed the findings of previous studies (Kos, 2004; Murray, 2009). Although teachers often have negative attitudes towards ADHD, they still try to use positive-oriented CMS. Also, teachers in both countries showed neutral attitudes towards negative-oriented CMS (neither positive nor negative attitudes), which also confirmed the findings of Kos's (2004) study. This result also shows that although corrective strategies were commonly used in the late 1990s (e.g., DuPaul \& Eckert, 1998), teachers currently favor more proactive strategies and emotional support (Kos, 2004; Murray, 2009). These findings imply that teachers organize the classroom and curriculum before students with ADHD misbehave in order to find out the strengths of students with ADHD to increase their self-esteem.

Hypothesis $1 b$ (subjective norms). Korean teachers were more influenced by the norms of their colleagues and the students' parents compared to German teachers, and both subjective norms are significantly different between countries. These findings can be explained by looking at the different cultural backgrounds of Korea and Germany, as confirmed by numerous studies (e.g., Hofstede, 2001). People from more individualistic cultures perceive themselves as "independent" in terms of their own preferences, and their norms are based on an individual level. On the other hand, people from more collectivistic cultures perceive themselves as "interdependent", belonging to groups as well as being motivated by norms (HoppeGraff \& Kim, 2005). In addition, Korean society's 
Confucianism might play a significant role in this finding. According to Confucian doctrine, individuals need to know the social order based on the hierarchies of age and social status (Hoppe-Graff \& Kim, 2005; Moon, 2001). Thus, Korean teachers are also expected to listen to other people (especially older teachers' or parents' recommendations), which does not apply in German culture.

Hypothesis 1c (perceived control over CMS). Both Korean and German teachers have a higher level of perceived behavioral control (PBC) of using all CMS. This result confirmed previous western studies (Blume-D'Ausilio, 2005; Kos, 2004), which found that teachers perceived that they would be able to effectively manage students with ADHD by using CMS. On the other hand, several Korean studies (Jeong \& Choi, 2007; Joo \& Jeong, 2007) reported that Korean teachers perceived a lack of control regarding the use of CMS. This finding implies that both Korean and German teachers are able to control the class using CMS they select as opposed to being influenced by other subjective norms such as those of colleagues and/or parents. Since Korean teachers tend to be more influenced by subjective norms, their higher $\mathrm{PBC}$ seems to be contradictory. Could it be possible for Korean teachers to have higher PBC, although they are influenced by other subjective norms? Actual behavior control will be an answer to compare their perceived behavior control.

Hypothesis 2a-2f (perceived control over CMS). The TRA proved to be better in predicting both Korean and German teachers' intentions of using CMS compared to the TPB, which was supported by the Webb and Sheeran (2006) study.

With respect to hypothesis $2 \mathrm{a} / 2 \mathrm{~b}$ (corrective strategies) and $2 \mathrm{c} / 2 \mathrm{~d}$ (proactive strategies), the TRA offered a significant contribution to predicting both Korean and German teachers' intentions of using these strategies for students of all vignette types, which was confirmed in previous studies (Webb \& Sheeran, 2006). These findings imply that teachers in both countries are more likely to use these corrective and proactive strategies when they have a favorable attitude towards them, and other subjective norms that are likely to be of support for them in using these strategies.

On the other hand, perceived behavior control (PBC) over CMS was not significantly improved for both Korean and German teachers' intentions of using these strategies, which is contradictory to the findings of Armitage and Conner (2001). According to Ajzen (1991), when individuals perceived that behavior control is high, and their attitude and subjective norms are favorable, then individuals' intentions to perform a particular behavior will be the strongest. It could be understood that teachers in both countries may have remarkable gaps between actual and perceived behavioral control.
With regard to hypothesis $2 \mathrm{e} / 2 \mathrm{f}$ (emotional support), the TRA offered a significant contribution to predicting only Korean teachers' intentions of using emotional support, but not German teachers. This implies that Korean teachers are more likely to use emotional support when they have a favorable attitude towards this strategy and when their colleagues and the parents of their students are likely to support them in using emotional support. On the other hand, German teachers are not more likely to use this strategy, although they have a favorable attitude toward this strategy, and their colleagues and the parents are likely to support them in using this strategy.

The TPB, on the other hand, offered a significant contribution to predicting German teachers' intentions of using emotional support (supported by Armitage and Conner's study, 2001), but not Korean teachers. For Korean teachers, it can be understood in the same vein of corrective and proactive strategies. For German teachers, their higher PBC increased teachers' intentions of using emotional support. This means that German teachers' PBC (with TRA predictors and/or PBC alone) significantly affected their intentions of using emotional support, so it seems that the PBC has a significant role for German teachers to try to use emotional support.

\section{CONCLUSIONS}

This study was a cross-cultural comparison between Korean and German teachers' CMS for students with $\mathrm{ADHD}$, based on the theoretical background of the TRA and the TPB. At present, little research has been conducted on this topic within a cross-cultural context (e.g., Norvilitis \& Fang, 2005), and few cross-cultural comparative studies have been conducted between Korea and Germany (e.g., Lee \& Witruk, 2013). This investigation proved the cross-cultural similarities (attitudes towards positive-oriented CMS, PBC over CMS) as well as differences (subjective norms). The TRA proved to significantly contribute to predicting both Korean and German teachers' intentions of using CMS (excluding German teachers' intentions of using emotional support). The TPB, however, proved to significantly contribute to predicting only German teachers' intentions of using emotional support.

This study is an important step towards understanding teachers' CMS in the cultural context of Korea and Germany. The findings of this study could be essential information to modify both theories based on different cultural perspectives. In addition, this investigation will be a preliminary resource to develop ADHD management to enhance teachers' confidence in managing students with ADHD in the classroom, so that both Korean and German teachers are able to be prepared for students with ADHD in their classroom, rather than give up on them. Also, this new 
framework could be applied to improve university education for pre-service teachers (i.e., prospective teachers) in developing their skills to manage students with ADHD, so that they are able to successfully prepare their future students with ADHD when they become teachers in the near future.

\section{RECOMMENDATIONS FOR FURTHER STUDIES}

First of all, the samples were teachers in Korea (collectivistic-vertical culture) and Germany (individualistic-vertical culture). Other cross-cultural research is suggested, especially with individual horizontal cultures (e.g., northern Europe) and collectivistic horizontal cultures (e.g., Israeli kibbutzim). Also, this study was only concerned with Korean and German teachers' CMS. It may not be accurate to generalize these research findings to other types of teachers. Other types of teachers (e.g., pre-service teachers) as well as other types of school (e.g., special schools) should be investigated in the future. In addition, asynchronous data collection was conducted in Korea and Germany due to the first author's visit to Korea during the semester break. The same period of data collection is suggested for further research (from the methodological limitations and delimitations).

Second, it is suggested to further investigate the environmental factors in advance, so that teachers are able to use proactive strategies and emotional support without hindrance (from hypothesis 1a). Future studies need to investigate this issue by dividing lower hierarch and hierarch groups within a culture (from hypothesis 1b). In addition, teachers' actual behavior control will need to be investigated to find out the solution to reduce gaps between two behavioral controls (from hypothesis 1c).

Last but not least, the TPB could not predict teachers' intentions of using CMS due to both Korean and German teachers' high perceived behavioral control. This future investigation will be the key to understanding the TPB (which was poorly predicted in this study) as well as finding the best modified model of both the TRA and the TPB from the Korean and the German perspective (from hypothesis $2 \mathrm{a}$ to $2 \mathrm{~d}$ ). In addition, it is recommended to conduct further research as to why German teachers are not trying to use more emotional support when they have a favorable attitude and the supportive norms in place (from hypothesis 2e and $\mathrm{f}$ ).

\section{ACKNOWLEDGEMENTS}

We would like to express our gratitude to Dipl.Psych. Thérèse Thuemler, Dr. Shally Novita, and Dr. Kay Hemmerling, who read earlier drafts of this paper and offered us insightful comments and sugges- tions. Also very special thanks to Prof. Hyeong-Keun $\mathrm{Yu}$, Dr. Won-Guk Cho, Prof. Siegfried Hoppe-Graff, and Dr. Ulrike Quast for helping us to collect the data in Korea and Germany.

\section{ENDNOTES}

1 From here on, Korea represents South Korea.

\section{References}

Abikoff, H. B., Jensen, P. S., Arnold, L. E., Hoza, B., Hechtman, L., Pollack, S., ... Wigal, T. (2002). Observed classroom behavior of children with ADHD: Relationship to gender and comorbidity. Journal of Abnormal Child Psychology, 30, 349-359.

Ajzen, I. (1991). The theory of planned behavior. Organizational Behavior and Human Decision Processes, 50, 179-211.

Ajzen, I., \& Fishbein, M. (1980). Understanding attitudes and predicting social behavior. Englewood Cliffs, NJ: Prentice-Hall.

Ajzen, I., \& Fishbein, M. (2005). The influence of attitudes on behavior. In D. Albarracín, B. T. Johnson, \& M. P. Zanna (eds.), The handbook of attitudes (pp. 173-221). Mahwah, NJ: Erlbaum.

Arcia, E., Frank, R., Sanchez-LaCay, A., \& Fernáindez, M. C. (2000). Teacher understanding of ADHD as reflected in attributions and classroom strategies. Journal of Attention Disorders, 4, 91-101.

Armitage, C. J., \& Conner, M. (2001). Efficacy of the theory of planned behavior: A meta-analytic review. British Journal of Social Psychology, 40, 471-499.

Barkley, R. A. (2007). School interventions for attention deficit hyperactivity disorder: Where to from here? School Psychology Review, 36, 279-286.

Bekle, B. (2004). Knowledge and attitudes about attention-deficit hyperactivity disorder (ADHD): A comparison between practicing teachers and undergraduate education students. Journal of Attention Disorders, 7, 151-161.

Blume-D'Ausilio, C. (2005). Sources of information and selected variables and their relationship to teachers' knowledge and attitudes regarding attention deficit hyperactivity disorder (ADHD) (Unpublished doctoral dissertation). Florida Atlantic University Boca Raton, Florida.

Cordier, R., Bundy, A., Hocking, C., \& Einfeld, S. (2010). Empathy in the play of children with attention deficit hyperactivity disorder. OTJR: Occupation, Participation and Health, 30, 122-132.

Department of Education, Training and Employment. (1999). Attention difficulties, poor impulse control, overactivity or ADHD: Teaching and managing children and school students. Adelaide: SA: Author.

DuPaul, G., \& Power, T. J. (2008). Improving school outcomes for students with ADHD Using the right 
strategies in the context of the right relationships. Journal of Attention Disorders, 11, 519-521.

DuPaul, G. J., \& Eckert, T. L. (1998). Academic interventions for students with attention-deficit/hyperactivity disorder: A review of the literature. Reading \& Writing Quarterly Overcoming Learning Difficulties, 14, 59-82.

Emmer, E. T., Evertson, C. M., \& Worsham, M. E. (2009). Classroom management for middle and high school teachers. Upper Saddle River, NJ: Pearson.

Fishbein, M., \& Ajzen, I. (1975). Belief, attitude, intention and behavior: An introduction to theory and research. Reading, MA: Addison-Wesley.

Greene, R. W., Beszterczey, S. K., Katzenstein, T., Park, K., \& Goring, J. (2002). Are students with ADHD more stressful to teach? Patterns of teacher stress in an elementary school sample. Journal of Emotional and Behavioral Disorders, 10, 79-89.

Groth, M. (2007). Naughty boys. Anti-social behaviour, ADHD and the role of culture. Thymos, 1, 111-113.

Guyer, B. P. (2000). ADHD: Achieving success in school and in life. Boston, MA: Allyn \& Bacon.

Hedin, L. R., Mason, L. H., \& Gaffney, J. S. (2011). Comprehension strategy instruction for two students with attention-related disabilities. Preventing School Failure, 55, 148-157.

Hofstede, G. (2001). Culture's consequences: Comparing values, behaviors, institutions and organizations across nations. Thousand Oaks, CA: Sage Publications.

Hoppe-Graff, S., \& Kim, H.-O. (2005). Understanding rights and duties in different cultures and contexts: Observations from German and Korean adolescents. Unpublished manuscript, Department of Education, University of Leipzig, Leipzig, Germany.

Jeong, J. S., \& Choi, J. O. (2010). An examination of elementary teachers' knowledge of ADHD, attitudes toward including children with ADHD, and use of behavior management strategies. The Journal of Special Education: Theory and Practice, 11, 371-393.

Joo, K.-H., \& Jeong, J.-J. (2007). An experiential analysis of elementary school teachers' emotional factors and responding process to children's aggressive behavior. The Journal of the Developmental Disabilities, 11, 23-42.

Jung, J.-S., \& Choi, J.-O. (2010). An examination of elementary teachers' knowledge of ADHD, attitudes toward including children with ADHD, and use of behavior management strategies. Special Education. Theory and Practice, 11, 371-393.

Kos, J. M. (2004). Primary school teachers' knowledge, attitudes, and behaviours toward children with Attention-Deficit/Hyperactivity Disorder (Unpublished doctoral dissertation). RMIT University, Melbourne, Australia.

Kos, J. M. (2008, September). What do teachers know, think and intend to do about ADHD? Teaching and learning and leadership. Paper presented at the European Conference on Educational Research, Göteborg, Sweden.
Lee, Y., \& Witruk, E. (2013, March). A Content-analysis of Korean teachers' perceptions and beliefs regarding students with ADHD: A comparison with U.S. studies. Paper presented at the Asian Conference on Psychology and the Behavioral Science, Osaka, Japan.

Moon, S. Y. (2011). Cultural perspectives on attention deficit hyperactivity disorder: A comparison between Korea and the US. Journal of International Business and Cultural Studies, 6, 1-11.

Montague, M., \& Warger, C. (1997). Helping students with attention deficit hyperactivity disorder succeed in the classroom. Focus on Exceptional Children, 30, $1-16$.

Murray, E. (2009). “Don't give up on them”: Managing attention deficit hyperactivity disorder in schools - what teachers and parents believe and know (Unpublished doctoral dissertation). Murdoch University, Perth, Australia.

Norvilitis, J. M., \& Fang, P. (2005). Perceptions of ADHD in China and the United States: A preliminary study. Journal of Attention Disorders, 9, 413-424.

Ohan, J. L., Cormier, N., Hepp, S. L., Visser, T. A. W., \& Strain, M. C. (2008). Does knowledge about attention-deficit/hyperactivity disorder impact teachers' reported behaviors and perceptions? School Psychology Quarterly, 23, 436-449.

Shavitt, S., Lalwani, A. K., Zhang, J., \& Torelli, C. J. (2006). The horizontal/vertical distinction in cross-cultural consumer research. Journal of Consumer Psychology, 16, 325-342.

Shin, S., \& Koh, M.-S. (2007). A cross-cultural study of teachers' beliefs and strategies on classroom behavior management in urban American and Korean school systems. Education and Urban Society, 39, 286-309.

Singelis, T. M., Triandis, H. C., Bhawuk, D. P. S., \& Gelfand, M. J. (1995). Horizontal and vertical dimensions of individualism and collectivism: A theoretical and measurement refinement. Cross-cultural Research, 29, 240-275.

Singh, I. (2008). ADHD, culture and education. Early Child Development and Care, 178, 347-361.

Theodorakis, Y., Bagiatis, K., \& Goudas, M. (1995). Attitudes toward teaching individuals with disabilities: Application of planned behavior theory. Adapted Physical Activity Quarterly, 12, 151-160.

Triandis, H. C. (2001). Individualism and collectivism: Past, present, and future. In D. Matsumoto (ed.), The handbook of culture and psychology (pp. 35-50). New York, NY: Oxford University Press.

Triandis, H. C., \& Gelfand, M. J. (1998). Converging measurement of horizontal and vertical individualism and collectivism. Journal of Personality and Social Psychology, 74, 118-128.

Webb, T. L., \& Sheeran, P. (2006). Does changing behavioral intentions engender behavior change? A meta-analysis of the experimental evidence. Psychological Bulletin, 132, 249-268. 